\title{
Research on Northeast Sichuan Under the Background of Rural Revitalization
}

\author{
Hanfang $\mathrm{Xiao}^{1, \text { a }}$, Wei $\mathrm{Wu}^{2, \text { b* }}$ \\ ${ }^{1}$ School of Logistics, Chengdu University of Information Engineering, Longquanyi District, Chengdu, Sichuan, China \\ ${ }^{2}$ School of Logistics, Chengdu University of Information Engineering, Longquanyi District, Chengdu, Sichuan, China \\ 15609039658@163.com \\ b*596687989@qq.com
}

\begin{abstract}
If the country wants to revitalize, the countryside must be revitalized. Under the background of the continuous deepening implementation of the national rural revitalization strategy, it is necessary to accelerate the development of rural revitalization industry and drive the rapid improvement of rural economy by industry. Based on the countryside with unique tourism potential, this paper builds models according to different resource categories, accurately divides and positions the countryside suitable for tourism development, deeply excavates the traditional culture and unique resources, constructs the strategy selection model, and puts forward scientific strategy suggestions. Through comprehensive application, the rural tourism industry can revitalize the rural economy from many aspects and promote it as experience.
\end{abstract}

Keywords: rural revitalization, rural tourism, Policy selection.

\section{INTRODUCTION}

In 2021, the No.1 Central Committee document " Opinions of the CPC Central Committee and the State Council on Comprehensively Promoting Rural Revitalization and Accelerating Agriculture and Rural Modernization clearly points out that it supports the development of leisure agriculture and rural tourism routes and improves the construction of relevant supporting facilities in the scenic spots. Rural problems in the new era are still the top priority. ${ }^{[1]}$ In the revitalization of rural tourism, it is necessary to protect traditional villages, traditional dwellings and historical and cultural rural villages. Northeast Sichuan is rich in natural resources, which is also a major potential driving point for rural tourism development. Rural areas can use characteristic resources to attract investment, and combined with relevant successful cases, to provide development strategies for the development of rural tourism development in various resource categories, to realize the revitalization of the tourism industry. ${ }^{[2]}$

\section{THE SIGNIFICANCE OF RURAL TOURISM RESOURCE POSITIONING}

Under the background of rural revitalization, all kinds of villages have characteristics and have the potential driving force of rapid development. With more and more urban population is willing to travel to rural areas, it has a more vigorous development impetus for villages relying on ethnic culture, natural scenery and other resources to develop the tourism industry with local characteristics. It can further enhance the cultural and economic competitiveness of rural areas, and give new strength to the better and faster realization of the rural revitalization strategy. ${ }^{[3]}$

\section{CATEGORY POSITIONING OF RURAL TOURISM DEVELOPMENT UNDER THE BACKGROUND OF RURAL REVITALIZATION}

\subsection{Basis for category positioning}

There are a wide variety of resources in rural areas in China. In the positioning of rural resource category, the local main resource categories should first be taken into account, and the resource has exploitable and sustainable utilization. According to the example of the successful development of rural tourism in China and the actual situation of rural tourism resources in Northeast Sichuan, the categories of rural tourism resources in Northeast Sichuan are divided. 


\subsubsection{Tourism type in the old revolutionary base areas}

Northeast Sichuan is an old revolutionary base area, which belongs to the scope of the Sichuan-Shaanxi revolutionary base area. Now built a batch of red culture tourism, 5A level scenic area deng xiaoping's former residence, $4 \mathrm{~A}$ level scenic area sichuan revolutionary base red army martyrs cemetery, guangyuan red army culture park, etc., there are many rich red culture tourism, this kind of tourism can not only drive the economic revitalization of the surrounding countryside, but also can vigorously carry forward China's red revolution culture.

\subsubsection{Traditional folk custom tourism type}

Most of the villages in northeast Sichuan are traditional, and some areas are ethnic minority villages with rich kinds of rural culture. Some villages will hold unique folk culture activities every year, such as Spring Festival Dance Fire Dragon and Cangxi Lantern Opera. Rural folk culture also includes local intangible cultural heritage, ancient musical instruments inherited to this day, and unique living customs. These folk cultures are all resources to boost the economy.

\subsubsection{Rural agricultural tourism type}

Northeast Sichuan terrain is mountainous hills, agricultural production, traditional farming culture, in the process of accelerating agricultural modernization, traditional farming culture is tending to disappear, with fish pond, farmland and other rural landscape comprehensive development, form large-scale rural agricultural tourism, can attract more urban residents into rural areas, use leisure time to feel the traditional rural life, wake up not only the memories, is also an optimistic attitude towards life.

\subsubsection{Natural scenery tourism type}

Northeast Sichuan mountain resources are rich, Qinling bus mountain through the northern region, eastern part of the sichuan basin, more natural scenery, karst mountain canyon, karst landform guangyuan, etc., are rare natural landscape resources, however, the area's rural economic development is relatively backward, precious natural landscape resources can play a huge role in boosting the rural economy. ${ }^{[4]}$

\subsection{Resegmentation method of category positioning}

The re-refinement of resources in Northeast Sichuan provides a more accurate positioning standard for the resource positioning of resources in Northeast Sichuan, and refines the old revolutionary base areas (A) into three small categories of revolutionary battles (A1), the former residence of revolutionary heroes (A2) and the Red Army station (A3). Traditional Folklore (B) is refined into four small categories: Intangible Cultural Heritage (B1), Material Cultural Heritage (B2), Unique Rural Custom (B3), and Ethnic Minority Culture (B4). Pastoral Agriculture (C) is refined into three small categories: traditional farming (C1), Modern Agriculture (C2), and Pastoral Agricultural Landscape (C3). Natural Landscape (D) is refined into three small categories: Mountain Natural Resources (D1), Basin Natural Resources (D2), and Hills Natural Resources (D3). ${ }^{[5]}$ The rural resource classification resubdivision model in Northeast Sichuan is shown in Figure1:

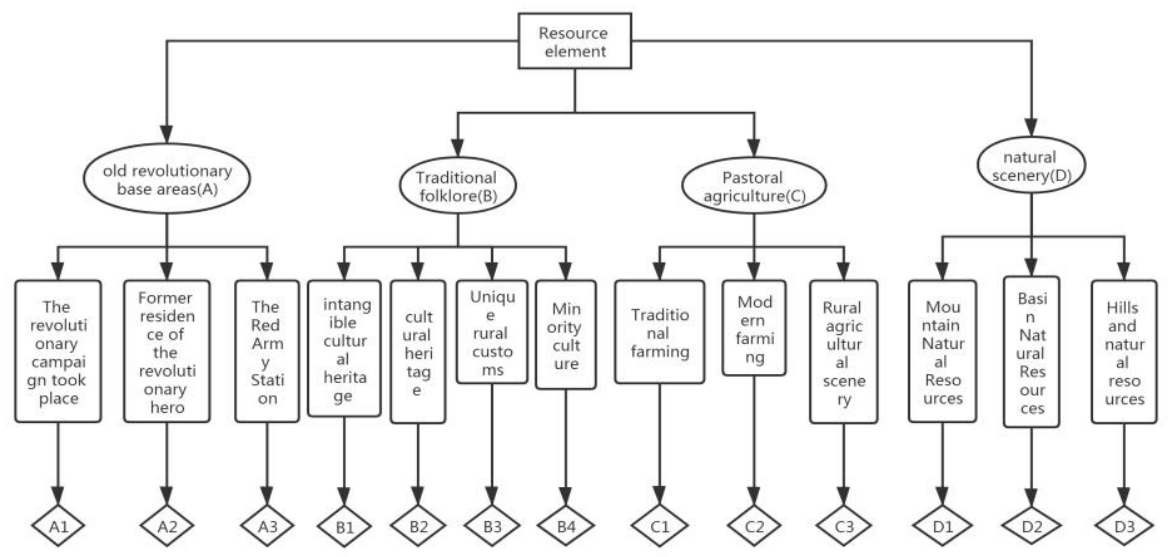

Figure 1: Rural resource category resegmentation model

\section{ANALYSIS OF THE TOURISM-TYPE RURAL DEVELOPMENT STRATEGY}

The 13 small categories are suggested based on the resubdivision model of rural resource category and the successful development examples of Northeast Sichuan. In Figure 3, in the Rural Resource Development Strategy Selection Model, K represents the available resource elements, R represents integrated utilization, E stands for independent development, $\mathrm{T}$ represents 
implementation projects. ${ }^{[6]}$ The resource elements are, respectivelyField cultural relics(K1), The battlefield occurred(K2), Campaign-related stories(K3), Campaign classics(K4), Revolutionary hero-related stories(K5), Life course of revolutionary heroes(K6), The great spirit of the revolutionary spirit(K7), History of resident forces(K8), Resident force history process(K9), Resident Force heroes(K10), traditional opera(K11), traditional skill(K12), $\quad$ song(K13), musical instrument(K14), historic building (K15), sculpture (K16), ruins(K17), Calligraphy books(K18), Etiquette and customs(K19), Marriage customs(K20), Daily life customs(K21), Family customs(K22), language(K23), festival(K24), food(K25), dress(K26), etiquette(K27), building(K28), music(K29), tool(K30), Historical development(K31), Farming techniques(K32), Terrterraces(K33), Pastoral surroundings(K34), Strange scenery(K35), rare animal (K36), rare plant (K37), Comfortable climate(K38), Mountains and rivers(K39), Ecological food(K40). Determine the fusion type and independent development type according to the nature, propose strategy suggestions, and finally based on each strategy proposal, the extension of implementable rural projects. As shown in Figure 2.

\subsection{Old revolutionary base areas, category}

Northeast Sichuan is the old revolutionary base area, with rich red revolution resources, marshal Zhu De former residence, Wanyuan war history hall and other revolutionary attractions have been developed, revolutionary base area tourism rural division of three resource types need to develop under the premise of protection, in rural revolutionary culture development, can introduce historical sitcom, in the local dynamic way of historical reproduction, reproduce the revolutionary years, tourists can more deeply feel the revolutionary culture. Shooting historical films or documentaries, broadcast in scenic spots, can be shown more vivid. Local and surrounding villages in the premise of further learning revolutionary culture, the government joint villagers build red countryside, in accommodation, catering, street, printed into the red revolutionary culture, service personnel dress, rural situational actors dress can be revolutionary main design, let tourists into the countryside, feel the revolution anytime and anywhere, enjoy the unique charm of rural tourism in patriotic education. ${ }^{[7]}$

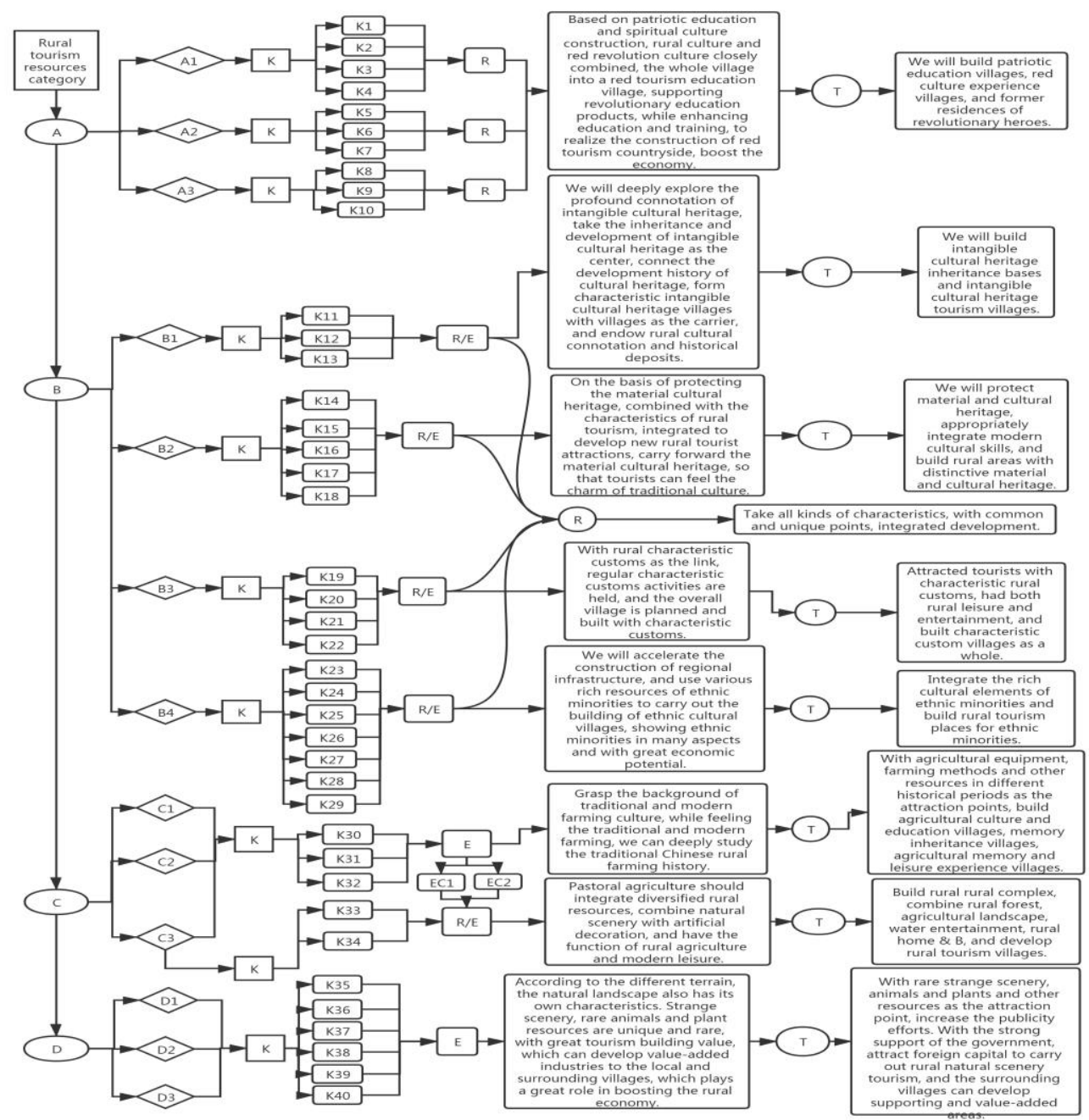

Figure 2: Selection model of rural resource development strate 


\subsection{Traditional folklore category}

Most of the intangible cultural and material cultural heritages, such as dazhou Baolong, puppet opera in northern Sichuan and northern Sichuan lantern opera in northeast Sichuan, have been preserved in rural areas. Tujia people living in Xuanhan County, give full play to the advantages of ethnic minority culture, combined with the long history of Pakistani culture, under the strong support of the government, implemented the characteristic rural cultural tourism poverty alleviation project, that is, the Bashan Grand Canyon according to the $5 \mathrm{~A}$ standard, has been promoted as a model of rural cultural revitalization. Rural revitalization first to explore the cultural characteristics of the village, under the traditional folk categories, some villages may belong to one category, may also have a variety of categories of elements, can be integrated development, in rural tourism, multifactor design, from architectural style, cultural and entertainment projects, can make tourists better understand love the local folk culture. If you belong to a single category, you can also take this approach.

\subsection{Rural agriculture category}

Northeast Sichuan rain, climate is suitable for plant growth, dazhou strawberry garden, blueberry garden, bazhong vineyards, etc., the use of local climate conditions, fruit planting, fruit planting, on the basis of fruit planting, combined with rural rural scenery, integrated picking experience village, rural landscape village, in leisure also can eat green melons and fruits, improve the experience. This category is divided into three small categories of rural resources, in northeast sichuan remote or economic development is relatively backward, no rural characteristics, can use agricultural traditional farming, from multiple resource elements, carry out traditional farming skills inheritance experience village, in different villages, using differentiation, develop the traditional farming education village with local characteristics. Modern farming can also make use of the differentiation of machinery and equipment, operation technology and production mode to the construction of agricultural education village, so as to develop rural economy and inherit farming culture.

\subsection{Natural scenery category}

Northeast northeast of Sichuan is of various types, mainly hills, mountains and basins, and rich in natural resources. Guangyuan Zengjiashan Scenic Area has high forest cover rate, with hundreds of rare animals and plants and plants, many karst caves and stone forests, which belongs to the summer summer spot and is rated as the national agricultural scenic spot. Northeast Sichuan is rich in natural resources, including unique scenic spots, rare animals and plants, suitable climate, etc. Therefore, the region to achieve rural revitalization, can actively use natural resources, build animal and plant science education base, leisure summer resort, forest health village, natural tourism scenic area, etc., the surrounding countryside can use scenic areas, the development of rural home stay industry, and other affiliated economic points, to drive the rural economic revitalization.

\section{CONCLUSION}

In the context of the rural revitalization strategy, only when we need to grasp the economic points that can enable rural revitalization, can we truly boost the rural economy. Through northeast Sichuan rural resources classification model, is roughly divided into four categories, then build subdivision model refinement rural resources classification, a total of 13 categories, small have in common between small and small classes, can be used, some rural resources types can only be developed separately, after the analysis of various resource elements, combined with the corresponding successful examples of rural revitalization, build rural resources development strategy selection model for rural areas with various kinds of resources. Rural resource category positioning and strategy selection methods can be extended to similar areas to accelerate the realization of the rural revitalization strategy.

\section{REFERENCES}

[1] Zhang Zhuoping. Promote the high-quality development of rural tourism with the concept of cultural and tourism integration: the formation of logic and path choice [J]. Nanjing Social Sciences, 07(2021): 157-164.

[2] Xu Hong, Li Jun. Mechanism and development strategy of rural revitalization driven by regional tourism development in ethnic minority areas [J]. Business Economic Research, 11(2021): 184-188.

[3] Han Boran. Rural tourism economy industry optimization and upgrading strategy $[\mathrm{J}]$. Social scientists, 04(2021): 52-57.

[4] Zhang Zhuoping. Innovation Suggestions for the Integrated Development of Cultural Tourism Industry and Ecological Agriculture under the Background of Rural Revitalization [J]. Administrative Reform, 05(2021): 64-70.

[5] Qin Xiaohua, Huang Wu, Xu Shaogui. Mechanism and path of rural tourism to help rural revitalization in poor areas of Guangxi border [J]. Jiangsu Agricultural Science, 10(2021): 1-6.

[6] Cui Jian, Wang Dan. The "triple theory domain" perspective of the high-quality development of 
rural tourism [J]. Agricultural Economy, 2021, $\{4\}$ (05): 46-47.

[7] He Xuan. Research on the connection between cultural and tourism integration and rural revitalization [J]. China Administration, 2021, $\{4\}$ (05): 155-157. 